\title{
Spring surface cooling trend along the East Asian coast after the late 1990s
}

\author{
LI Fei ${ }^{1,2,3^{*}} \&$ WANG HuiJun ${ }^{1,2}$ \\ ${ }^{1}$ Nansen-Zhu International Research Center, Institute of Atmospheric Physics, Chinese Academy of Sciences, Beijing 100029, China; \\ ${ }^{2}$ Climate Change Research Center, Chinese Academy of Sciences, Beijing 100029, China; \\ ${ }^{3}$ University of Chinese Academy of Sciences, Beijing 100049, China
}

Received November 21, 2012; accepted March 8, 2013; published online May 9, 2013

\begin{abstract}
This paper presents the surface cooling trend observed in spring along East Asia coast after the late 1990s, in contrast to the global warming trend. This surface cooling trend is comprehensible as it agrees well with the cooling of sea surface temperature (SST) in the northwestern Pacific and the weakening of $300 \mathrm{hPa}$ East Asian jet (EAJ) during spring. Moreover, this cooling phenomenon has been shown to be related to the rapid decline of Arctic sea ice cover (SIC) in previous autumns. The Arctic SIC signals in previous autumns can continue in spring and act as enhanced moisture sources that support the increased snow cover in Siberia during spring. The increased Siberian snow cover possibly favors the southward invasion of cold air masses via strong radiative cooling and large-scale descending motion, which may contribute indirectly to the reduction of temperature in East Asia. In addition, three climate models that can reproduce well the East Asian spring surface cooling observed in the past predicted uncertainty in the spring temperature projection in the next decade.
\end{abstract}

surface air temperature, cooling trend, sea ice cover, snow cover, cold air

Citation: $\quad$ Li F, Wang H J. Spring surface cooling trend along the East Asian coast after the late 1990s. Chin Sci Bull, 2013, 58: 3847-3851, doi: 10.1007/s11434013-5853-8

While the mean temperature near the surface of the planet has been continuously increasing since the late 1970s [1], the spatial patterns of temperature changes have been highly non-uniform [2,3]. East Asia is bordered in the east by the Pacific Ocean and in the southwest by the Tibetan Plateau. The unique geographic features produce distinct climate characteristics in East Asia [4]. Wang [5] indicated that the air temperature in middle troposphere over South China has been exhibiting a cooling trend since the late 1970s, which is in contrast with the common warming trend observed elsewhere. Besides, a similar cooling trend exists in case of surface temperature as well.

Previous studies have shown that factors that influence the East Asian climate include the thermal contrast between Asia and the North Pacific [6,7], Arctic sea ice [8-10], Tibetan Plateau heating [11], and so on. The Arctic sea ice

*Corresponding author (email: lifei-715@163.com) represents an important and highly variable component of the global climate system. Satellite data have revealed rapid Arctic warming since the 1990s [12-14]. The Arctic forcing linked to the sea ice cover (SIC) variability thus has become more important and is receiving more attention in recent years [15-18]. Liu et al. [19] indicated that the Arctic sea ice has substantial impact on the winter temperature and snowstorm activity. Here evidence is presented to show a relationship between the surface cooling signals in spring and the loss of previous autumn Arctic SICs after the late 1990s.

\section{Surface cooling trend in spring along the East Asia coast observed after the late 1990s}

Based on the atmospheric data obtained from the National Centers for Environmental Prediction (NCEP) reanalysis 
[20], we examined the linear trends of surface air temperature (SAT) in spring (Mar-May) during the past 15 years (1998-2012), as shown in Figure 1(a). A strong surface cooling trend has been observed along the East Asia coast. This is in contrast with the strong surface warming trend that covers the Arctic region, Europe, and Siberia. The time series of the area-mean $\operatorname{SAT}\left(15^{\circ}-50^{\circ} \mathrm{N}, 100^{\circ}-160^{\circ} \mathrm{E}\right)$ is shown in Figure 2. It exhibits a sharp increase around the year 1998, and the declining tendency is observed only after the late 1990s.

Similar to the SAT trend described above, we performed a linear trend analysis of spring sea surface temperature (SST; based on the data from the National Oceanic and Atmospheric Administration (NOAA) [21]) and $300 \mathrm{hPa}$ zonal wind (U300). Evidently, coherent SST cooling occurs in the northwestern Pacific, but SST warming occurs in the central northern Pacific (Figure 1(b)). The upper troposphere westerly jet stream is one of the most important circulation systems in East Asia. From Figure 1(c), a moderate easterly
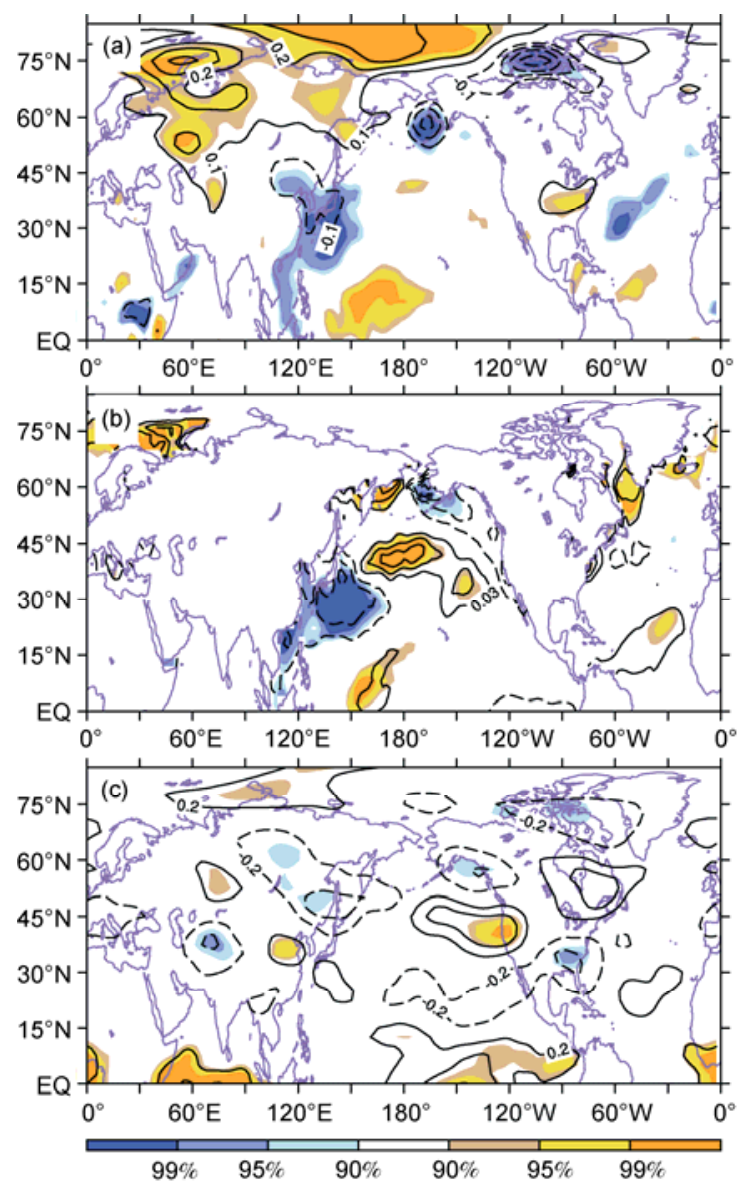

Figure 1 (a) Linear trends of spring surface air temperature (SAT) during the past 15 years (1998-2012). Contour interval is $0.1^{\circ} \mathrm{C} / \mathrm{a}$. (b) Same as in Figure 1(a), except for spring sea surface temperature (SST). Contour interval is $0.03^{\circ} \mathrm{C} / \mathrm{a}$. (c) Same as in Figure 1(a), except for spring $300 \mathrm{hPa}$ zonal wind (U300). Contour interval is $0.2 \mathrm{~m} \mathrm{~s}^{-1} \mathrm{a}^{-1}$. Shaded regions represent $90 \%, 95 \%$, and $99 \%$ confidence intervals, as estimated using a Student's $t$-test. trend can be seen in the region extending from central Siberia southeastward to northern Japan and a moderate westerly trend in the region to the south. As such, the $300 \mathrm{hPa}$ East Asian jet (EAJ), defined as the time series of the area-mean difference $\mathrm{U} 300\left(42^{\circ}-52^{\circ} \mathrm{N}, 120^{\circ}-160^{\circ} \mathrm{E}\right)$ minus $\mathrm{U} 300$ $\left(30^{\circ}-40^{\circ} \mathrm{N}, 100^{\circ}-140^{\circ} \mathrm{E}\right)$, tends to weaken, which is dynamically consistent with the decrease in latitudinal temperature gradient. Both the time series of the area-mean SST $\left(15^{\circ}-40^{\circ} \mathrm{N}, 120^{\circ}-160^{\circ} \mathrm{E}\right)$ and the EAJ index have been exhibiting significant declining tendencies after the late 1990s.

In summary, above results support the finding that surface cooling along the East Asian coast in spring has been occurring since the late 1990s, combined with the SST cooling in the northwestern Pacific and the weakened 300 $\mathrm{hPa}$ EAJ. A pertinent question to ask would be what factors contribute to the East Asian surface cooling?

Shown in Figure 3(a) is the linear trend of autumn SIC during the past 15 years (1997-2011). We calculated autumn SIC using the 3-month (Sep-Nov) mean concentration fields of the Hadley Centre sea ice and SST dataset version 1 (HadISST1) [22]. It was observed that the SIC declined rapidly in previous autumns, with the largest sea ice loss occurring from the Laptev Sea to the Beaufort Sea. The time series of the area-mean previous autumn SICs $\left(75^{\circ}-82^{\circ} \mathrm{N}, 90^{\circ}-120^{\circ} \mathrm{W}\right)$ is shown in Figure 2, which shows significantly larger interannual variability after the late 1990s than before. Meanwhile, an obvious declining tendency is observed in the later period.

Thus, the impacts of Arctic SIC on East Asian climate appear to have been enhanced after the late 1990s. We investigated this enhancement by analyzing the linear regressions of spring snow cover (from the Northern Hemisphere $25 \mathrm{~km}$ Equal Area Earth Grids (EASE-Grids) Snow Water

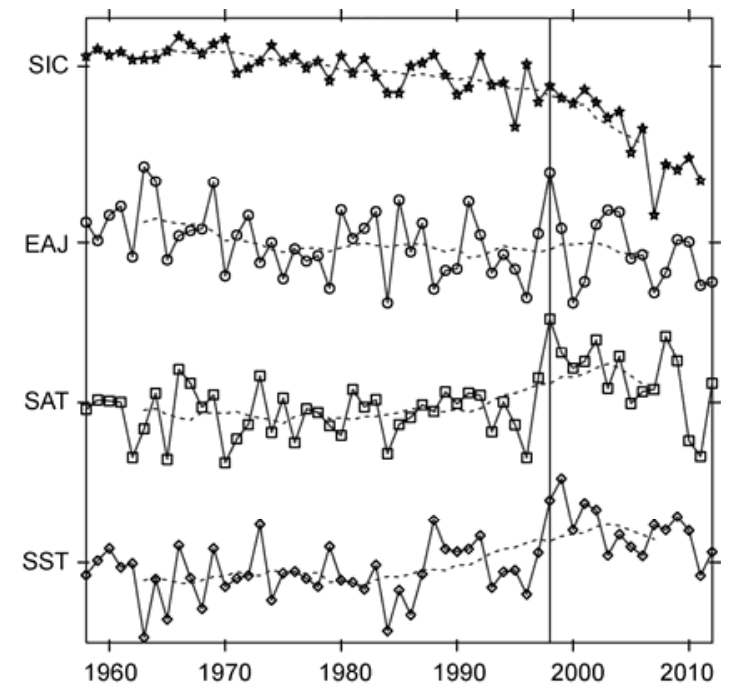

Figure 2 1958-2012 time series of the previous autumn sea ice cover (SIC), spring East Asian jet (EAJ), surface air temperature (SAT), and sea surface temperature (SST) indices, which are standardized (but not detrended). Solid lines represent yearly variations and dashed lines represent the 11-year running mean. 

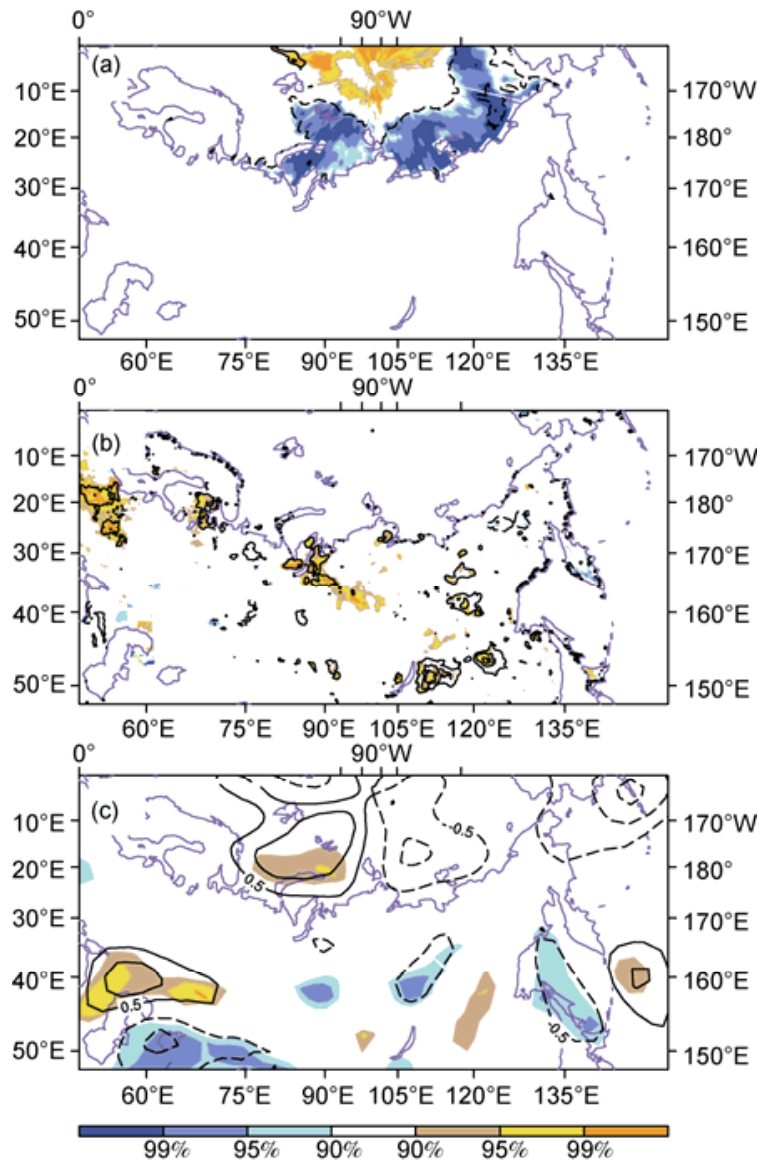

Figure 3 (a) Linear trends of autumn sea ice cover (SIC) during the past 15 years (1997-2011). Contour interval is $30 \mathrm{~km}^{2} / \mathrm{a}$. (b) Linear regressions of spring snow cover upon the negative previous autumn SIC index during 1998-2007. Contour interval is $10 \mathrm{~mm}$. (c) Same as in (b), except for spring $1000 \mathrm{hPa}$ meridional wind (V1000). Contour interval is $0.5 \mathrm{~m} / \mathrm{s}$. Shaded regions represent $90 \%, 95 \%$, and $99 \%$ confidence intervals, as estimated using a Student's $t$-test.

Equivalent Climatology available for 1978-2007 [23]) and $1000 \mathrm{hPa}$ meridional wind (V1000) upon the negative previous autumn SIC index from 1998 to 2007. The reduction of SIC corresponds to the enhanced moisture sources that support increased snow cover in Siberia in spring (Figure 3(b)), as discussed by Liu et al. [18]. Moreover, Figure 3(c) shows a close association between the loss of SIC and the northerly anomalies in Siberia and Mongolia in spring. The findings discussed here suggest that these anomalous northerlies are, in part, a result of the increased Siberian snow cover via its strong radiative cooling and large-scale descending motion. The southward invasion of cold air masses may contribute indirectly to the reduction in temperature in East Asia.

Furthermore, we examined the linear regressions of spring SAT, SST, and U300 upon the negative previous autumn SIC index from 1998 to 2012 (Figure 4). We found previous autumn SIC signals in East Asia, which strongly resemble Figure 1 in spatial patterns. The decrease in SIC corresponds to negative SAT anomalies along the East Asia
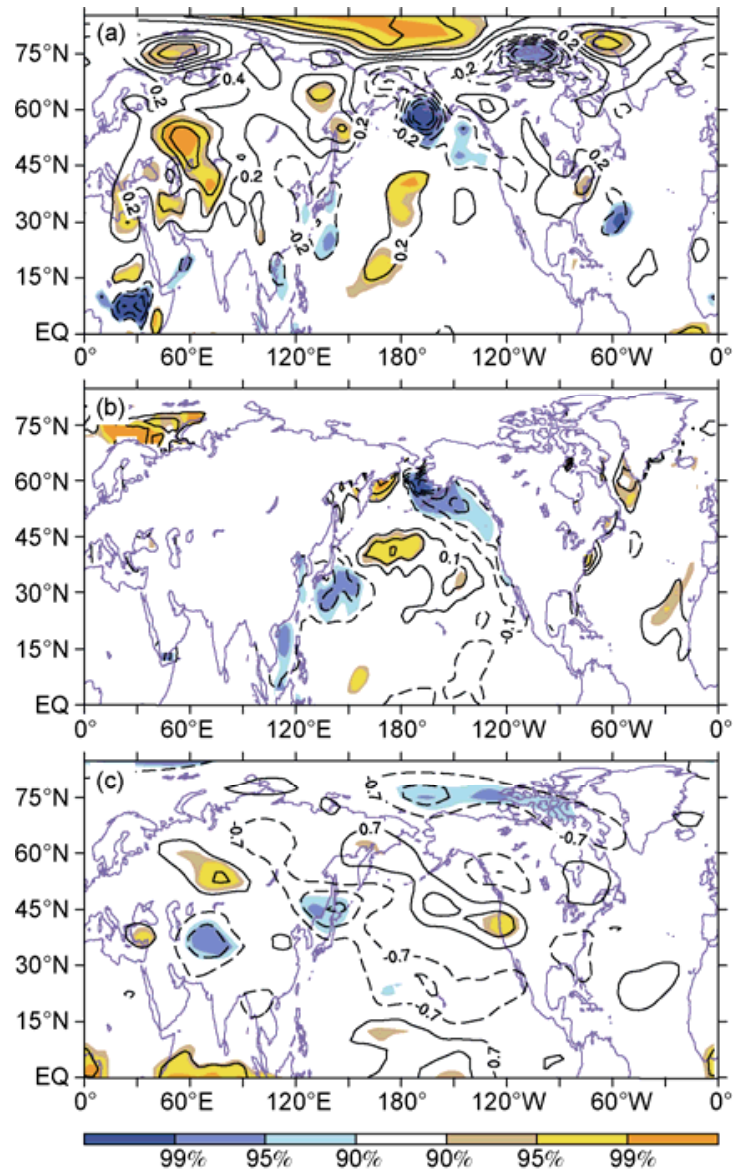

Figure 4 (a) Linear regressions of spring surface air temperature (SAT) upon the negative previous autumn sea ice cover (SIC) index from 1998 to 2012. Contour interval is $0.2^{\circ} \mathrm{C}$. (b) Same as in (a), except for spring sea surface temperature (SST). Contour interval is $0.1^{\circ} \mathrm{C}$. (c) Same as in (a), except for spring $300 \mathrm{hPa}$ zonal wind (U300). Contour interval is $0.7 \mathrm{~m} / \mathrm{s}$. Shaded regions represent $90 \%, 95 \%$, and $99 \%$ confidence intervals, as estimated using a Student's $t$-test.

coast and positive SAT anomalies in the Arctic region, southern Europe, and Siberia. Meanwhile, coherent negative SST anomalies occur in the northwestern Pacific and positive SST anomalies in the central northern Pacific. The 300 $\mathrm{hPa}$ EAJ is weakened greatly under such circumstances, in conjunction with a decrease in the latitudinal temperature gradient.

In addition, we investigated the spring surface cooling trend in East Asia during a warming climate, characterized by continued loss of Arctic sea ice, using the simulations from CMIP5 (phase five of the Coupled Model Intercomparison Project; see http://cmip-pcmdi.llnl.gov/). In this study, we focused on the historical simulation available from 1998 to 2005 and projection simulation under the RCP4.5 scenario (referred to as "representative concentration pathways") from 2020 to 2029. Our preliminary analysis showed that three models (GFDL-ESM2M, IPSLCM5A-MR, and MPI-ESM-MR) could capture better the East Asian spring surface cooling observed in the past, as shown in Figure 5(a)-(c). 

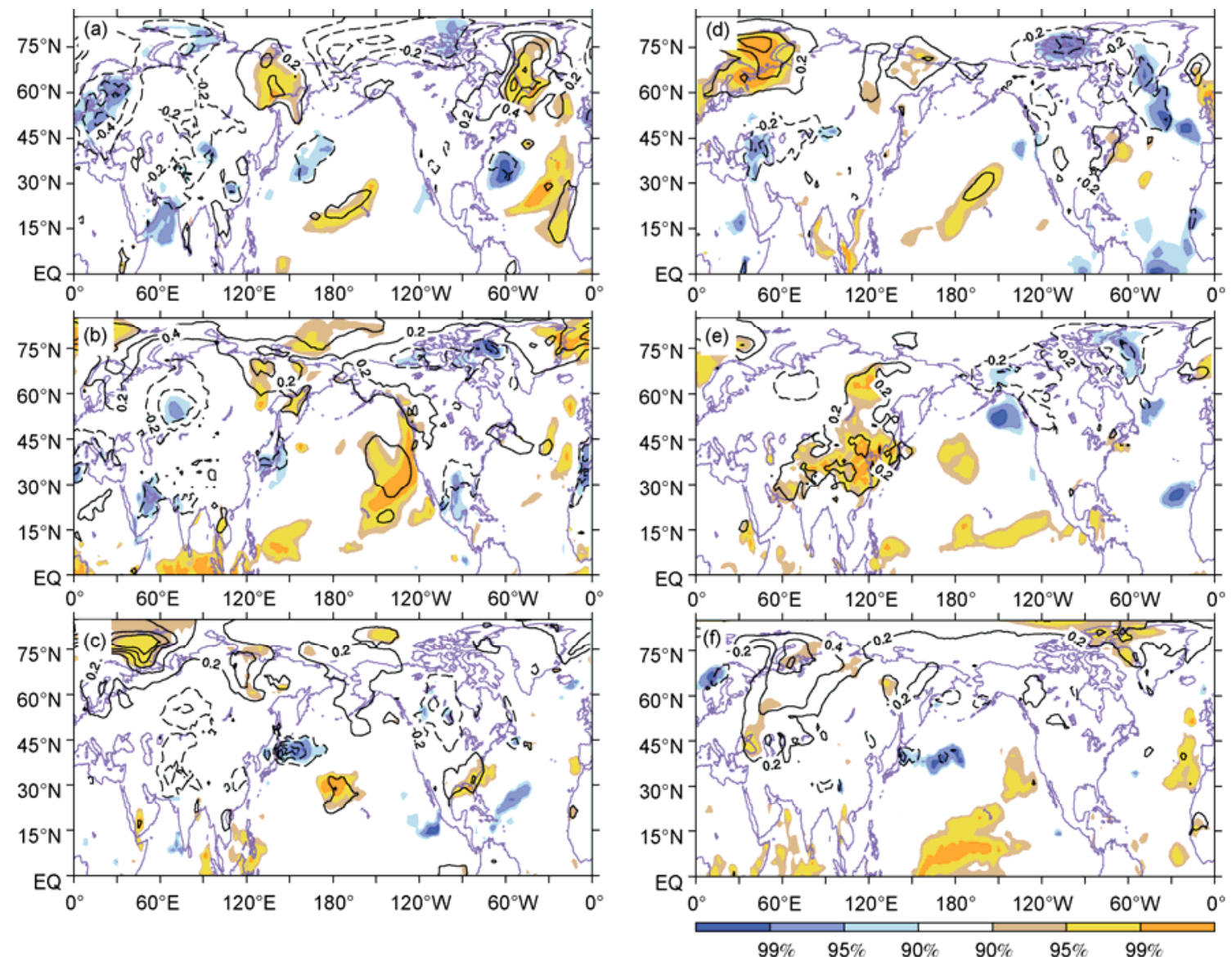

Figure 5 (a)-(c) Linear trends of spring surface air temperature (SAT) observed in the past (1998-2005), based on the simulation from GFDL-ESM2M, IPSL-CM5A-MR, and MPI-ESM-MR. Contour interval is $0.2^{\circ} \mathrm{C} / \mathrm{a}$. (d)-(f) Same as in (a)-(c), except for the next decade (2020-2029). Shaded regions represent $90 \%, 95 \%$, and $99 \%$ confidence intervals, as estimated using a Student's $t$-test.

Based on the results obtained using GFDL-ESM2M, IPSL-CM5A-MR, and MPI-ESM-MR, we also plotted the linear trends in the next decade (2020-2029) in spring SAT. Figure 5(d)-(f) indicates that there are many cases with large uncertainties in the temperature trends over East Asia, with model simulations ranging from no trends (GFDLESM2M) to substantially positive trends (IPSL-CM5A-MR) to negative trends (MPI-ESM-MR). This might be a result of the integral effects of radiative forcing induced by the greenhouse gas increase and the associated feedbacks of the atmospheric circulation, cloud and precipitation, and sea ice, to the temperature change. These complex feedbacks constitute the uncertainty of the spring temperature projection in the next decade.

\section{Conclusion}

In this work, we have shown that SAT along the East Asian coast has been exhibiting a strong surface cooling trend in spring since the late 1990s, which may significantly be correlated with the rapid decline of Arctic SIC in previous autumns. The main reasons are as follows:
(1) The Arctic SIC signals may act as enhanced moisture sources that support the increased snow cover in Siberia.

(2) The memory of Arctic SIC and Siberian snow cover anomalies can continue from previous autumn to spring.

(3) The increased Siberian snow cover possibly favors the southward invasion of cold air masses via strong radiative cooling and large-scale descending motion, which may contribute indirectly to the reduction in temperature in East Asia.

In addition, three CMIP5 climate models that could reproduce well the East Asian spring surface cooling observed in the past suggested uncertainty of the spring temperature projection during 2020-2029 as compared to that during 1998-2005.

This work was supported by the National Natural Science Foundation of China (41130103 and 41210007) and the CAS-CSIRO Cooperative Research Program (GJHZ1223).

1 Hegerl G C, Zwiers F W, Braconnot P, et al. Understanding and attributing climate change. In: Solomon S, Qin D, Manningedited M, et al., eds. Climate Change 2007: The Physical Science Basis. Cambridge: Cambridge University Press, 2007. 663-745 
2 Trenberth K E, Jones P D, Ambenje P, et al. Observations: Surface and atmospheric climate change. In: Solomon S, Qin D, Manningedited M, et al., eds. Climate Change 2007: The Physical Science Basis. Cambridge: Cambridge University Press, 2007. 253-336

3 Falvey M, Garreaud R D. Regional cooling in a warming world: Recent temperature trends in the southeast Pacific and along the west coast of subtropical South America (1979-2006). J Geophys Res, 2009, 114: D04102

4 Wang W C, Gong W, Wei H. A regional model simulation of the 1991 severe precipitation event over the Yangtze-Huai river valley. Part I: Precipitation and circulation statistics. J Clim, 2000, 13: 74-92

5 Wang H J. The weakening of the Asian monsoon circulation after the end of 1970's. Adv Atmos Sci, 2001, 18: 376-386

6 Zhou B, Zhao P. Influence of the Asian-Pacific oscillation on spring precipitation over central eastern China. Adv Atmos Sci, 2010, 27: 575-582

7 Li F, Wang H J. Predictability of the East Asian winter monsoon interannual variability as indicated by the DEMETER CGCMS. Adv Atmos Sci, 2012, 29: 441-454

8 Zhao $\mathrm{P}$, Zhang $\mathrm{X}$, Zhou $\mathrm{X}$, et al. The sea ice extent anomaly in the North Pacific and its impact on the East Asian summer monsoon rainfall. J Clim, 2004, 17: 3434-3447

9 Li F, Wang H J. Relationship between Bering Sea ice cover and East Asian winter monsoon year-to-year variations. Adv Atmos Sci, 2013, 30: $48-56$

10 Li F, Wang H J. Autumn sea ice cover, winter northern hemisphere annular mode and winter precipitation in Eurasia. J Clim, 2013, 26: 3968-3981

11 Wang $\mathrm{Y}$, Zhao $\mathrm{P}, \mathrm{Yu}$ R, et al. Inter-decadal variability of Tibetan spring vegetation and its associations with eastern China spring rainfall. Int J Climatol, 2010, 30: 856-865
12 Maslanik J A, Fowler C, Stroeve J, et al. A younger, thinner Arctic ice cover: Increased potential for rapid, extensive sea-ice loss. Geophys Res Lett, 2007, 34: L24501

13 Nghiem S V, Rigor I G, Perovich D K, et al. Rapid reduction of Arctic perennial sea ice. Geophys Res Lett, 2007, 34: L19504

14 Serreze M C, Holland M M, Stroeve J. Perspectives on the Arctic's shrinking sea-ice cover. Science, 2007, 315: 1533-1536

15 Fan K. North Pacific sea ice cover, a predictor for the western North Pacific typhoon frequency? Sci China Ser D-Earth Sci, 2007, 50: 1251-1257

16 Wang H J, Sun J Q. Variability of Northeast China river break-up date. Adv Atmos Sci, 2009, 26: 701-706

17 Ma J H, Wang H J, Zhang Y. Will boreal winter precipitation over China increase in the future? The AGCM simulation under summer "ice-free Arctic" conditions. Chin Sci Bull, 2012, 57: 921-926

18 Wang H J, Sun J Q, Chen H P, et al. Extreme climate in China: Facts, simulation and projection. Meteor Z, Fast Track, 2012, 21: 279-304

19 Liu J P, Curry J A, Wang H J, et al. Impact of declining Arctic sea ice on winter snowfall. Proc Natl Acad Sci USA, 2012, 109: 40744079

20 Kalnay E, Kanamitsu M, Kistler R, et al. The NCEP/NCAR 40-year reanalysis project. Bull Amer Meteorol Soc, 1996, 77: 437-472

21 Smith T M, Reynolds R W, Peterson T C, et al. Improvements to NOAA's historical merged land-ocean surface temperature analysis (1880-2006). J Clim, 2008, 21: 2283-2296

22 Rayner N A, Parker D E, Horton E B, et al. Global analyses of sea surface temperature, sea ice, and night marine air temperature since the late nineteenth century. J Geophys Res, 2003, 108: 4407

23 Armstrong R L, Brodzik M J, Knowles K, et al. Global monthly EASE-Grid snow water equivalent climatology. Boulder, CO: National Snow and Ice Data Center, Digital Media, 2005

Open Access This article is distributed under the terms of the Creative Commons Attribution License which permits any use, distribution, and reproduction in any medium, provided the original author(s) and source are credited. 